\title{
Seismic, structural, and individual factors associated with earthquake related injury
}

\author{
C Peek-Asa, M Ramirez, H Seligson, K Shoaf
}

Injury Prevention 2003;9:62-66

Background: Earthquakes cause thousands of deaths worldwide every year, and systematic study of the causes of these deaths can lead to their prevention. Few studies have examined how multiple types of risk factors are related to physical injury during an earthquake.

Methods: A population based case-control study was conducted to examine how individual characteristics, building characteristics, and seismic features of the 1994 Northridge, California, earthquake contributed to physical injury. Cases included fatal and hospital-admitted injuries caused by the earthquake. Controls were drawn from a population based phone survey of county residents. Cases were

See end of article for authors' affiliations

Correspondence and requests for reprints to: Corinne Peek-Asa, lowa Injury Prevention Research Center, University of lowa College of Public Health, 100 Oakdale Campus \# 114 IREH, lowa City, IA 52242-5000, USA: corinne-peek-asa@uiowa.edu individually matched to two sets of controls: one matched by age and gender and one matched by location at the time of the earthquake.

Results: Individuals over age 65 had 2.9 times the risk of injury as younger people $195 \%$ confidence interval (CI) 1.2 to 7.4 ) and women had a 2.4 times greater risk than men (95\% Cl 1.2 to 5.1$)$. Location in multiple unit residential and commercial structures each led to increased injury risk compared with single unit residential structures, but the exact estimate varied depending on the control group used. With every increase in ground motion of $10 \%$ g, injury risk increased 2.2 times $(95 \% \mathrm{Cl} 1.6$ to 3.3).

Conclusions: Controlling for other factors, it was found that individual, building, and seismic characteristics were independently predictive of increased injury risk. Prevention and preparedness efforts should focus on each of these as potential points of intervention.

E ach year, approximately 16 earthquakes occur throughout the world that result in significant loss of human life. ${ }^{12}$ With a growing world population, increasing urbanization, and new research that shows catastrophic earthquakes to be more highly correlated than previously indicated, ${ }^{3}$ populations are becoming more vulnerable to death from large earthquakes.

The number of reported deaths varies by earthquake, even among earthquakes of similar magnitude that affect highly populated areas. Table 1 lists the number of reported deaths among some recent earthquakes with Richter scale magnitude over 6.5 that affected urban areas. ${ }^{1248}$ Among these is the Northridge, California, earthquake that occurred at approximately 4:30 am on 17 January 1994 and led to 33 traumatic deaths and an additional 138 hospital-admitted injuries. ${ }^{9}$

Variation in the number of earthquake deaths can be attributed to at least three distinct categories of risk factors. First, seismic/geophysical factors describe the magnitude and location of the earthquake, as well as the distribution of ground motion. Second, building factors describe the structural integrity of buildings in which people are located during earthquakes. Third, individual human characteristics are related to the ability to respond to an earthquake and physical resiliency. Variation in the number of reported deaths and injuries may also be explained by differing case definitions and ability to conduct complete counts of injured individuals.

While structural failure of a building is generally recognized as the most common cause of death in large earthquakes, ${ }^{12}$ the relationship between seismic/geophysical, structural, and personal risks has not been simultaneously investigated for the same earthquake. Although studies have examined seismic risk factors, ${ }^{70-13}$ demographic characteristics, ${ }^{79}{ }^{11-16}$ and building characteristics ${ }^{13} 1^{17-19}$ as they relate to injury, no other study has examined these simultaneously while using exposure matched controls. Studies have not explored these risks simultaneously because the data, in countries that are able to collect it at all, are usually collected by different agencies and often not linkable at the individual level. We were able to link individual data from medical records, population surveys, engineering and seismology databases and maps, and county tax assessor files to measure variables in each of the three categories of risk factors. The goal of this analysis is to identify the independent contribution of each category of risk factor to the risk of physical injury related to an earthquake.

\section{METHODS}

A population based case-control study was conducted to determine the risk of earthquake related physical injury for the three groups of risk factors. Two sets of controls were selected. The first set was individually matched to cases based on the closest geographic location at the time of the earthquake to control for seismic characteristics; the second set was individually matched on age and gender to control for personal characteristics.

\section{Injury cases}

Cases were adults aged 18 years or older who sustained a fatal or hospital-admitted injury as a direct result of the earthquake. Because building characteristics are one of the main risk factors examined in this analysis, individuals who were not in a building at the time of their injury were excluded.

Fatal cases were identified through the Los Angeles County Coroner's Office. The Coroner's Office reported a total of 58 earthquake related deaths, of which 33 were due to physical injuries. Earthquake related hospitalized injuries were sought in all 78 acute care hospitals in Los Angles County. Individual

Abbreviations: $\mathrm{Cl}$, confidence interval; $\mathrm{MMI}$, modified Mercalli intensity (scale); PGA, peak ground acceleration 
Table 1 Variation in reported deaths in large earthquakes near urban centers

\begin{tabular}{llll}
\hline Location & Year & $\begin{array}{l}\text { Richter scale } \\
\text { magnitude }\end{array}$ & Reported deaths \\
\hline China & 1976 & 7.8 & 242000 \\
Guatemala & 1976 & 7.5 & 22778 \\
Mexico City & 1985 & 8.1 & 10000 \\
Armenia & 1988 & 6.9 & 24944 \\
Loma Prieta, CA & 1989 & 7.1 & 61 \\
India & 1993 & 6.5 & 9475 \\
Northridge, CA & 1994 & 6.9 & 58 \\
Indonesia & 1994 & 6.5 & 207 \\
Indonesia & 1994 & 6.9 & 1 \\
Japan & 1995 & 7.2 & 6308 \\
Seattle, WA & 2000 & 6.8 & 1 \\
\hline
\end{tabular}

records were reviewed in 16 of the 78 hospitals that had evidence of earthquake related injury admissions, and a total of 138 were identified. Detailed methodology of data collection of cases is described in an earlier study. ${ }^{9}$

Of the 171 fatal and hospital-admitted injuries, 131 met the case criteria of age 18 years or older, being in a building during the earthquake, and having injuries directly related to the earthquake (excluding, for example, aftershock injuries). Of these 131 eligible cases, 28 (21.4\%) were excluded because the given address during the earthquake did not link with building and structural databases. This left 103 (78.6\%) cases with geocodable addresses that linked to building databases.

\section{Control selection}

Controls were selected from a population based survey conducted after the earthquake to describe earthquake experiences. ${ }^{20}$ This survey included interviews with 1831 households chosen by random digit dialing in Los Angeles County. Interviews were conducted from six to 24 months after the earthquake in three separate waves that achieved response rates ranging from 40\%-60\%. Eligible households were identified using the Computer Assisted Telephone Interviewing system. Interviews were conducted in English and Spanish. Only adults who identified themselves as not injured but present in Los Angeles County and in a building during the time of the earthquake were eligible as controls for this analysis.

Matching was conducted to adjust for confounding of other risk factors among the interrelated exposure categories. For each case, two individually matched controls were selected from the pool of eligible controls. Age and gender matched controls were matched to cases based on same gender and age within one year. To select the geographically matched controls, latitude and longitude coordinates for all locations were identified using ArcView. ${ }^{10}$ Distance measurements were then calculated from each case to all controls within a five mile radius. The control with the shortest distance to the case was selected. When multiple cases were located at the same address, controls in closest proximity were randomly assigned.

Address matching produced 92 eligible controls for the 103 cases: 81 controls were used once and 11 controls were used twice. These 11 controls were used twice because of the concentration of cases near the earthquake epicenter and the limited pool of controls within that area. On average, controls were located 1.13 miles from cases.

\section{Key variables}

Seismic/geophysical variables included measurements of shaking intensity, strong ground motion, distance from the rupture plane, and soil type. Shaking intensity was measured using the modified Mercalli intensity (MMI) scale, which divides intensity into 12 levels based on qualitative shaking experience. At level I, the earthquake is felt by very few people, while at level XII few structures are left standing. ${ }^{2}$ The Northridge earthquake MMI levels ranged from V to IX, with IX indicating considerable damage to well designed structures. MMI levels were assigned by mapping each case and control location onto isoseismal MMI maps published by the United States Geological Survey and then identifying the underlying MMI level. ${ }^{21}$

Ground motion as measured by peak ground acceleration (PGA, \% gravity) was determined from TriNet ShakeMap grid based data for the Northridge Earthquake, which is available on the web (www.trinet.org).22 Acceleration was measured by seismic sensors and then interpolated between sensors to develop regional ground shaking maps. PGA values for each case and control location were assessed by mapping coordinates onto the TriNet ShakeMap.

Soil type categories were limited to rock and sedimentary soil. Soil type was determined by mapping case and control coordinates onto a surficial geology map developed by researchers at the Southern California Earthquake Center. ${ }^{23}$ Distance from each case and control to the rupture plane was calculated based on fault plane coordinates developed by Wald et al. $^{24}$ The rupture plane is a three dimensional area from which ground motion originates, and it best represents the closest origin of ground motion.

Building characteristics included the year of construction, building use, and the presence of building damage. Building use was categorized as single family residences, multiple family residences, and commercial/other buildings. Other buildings included parking structures, sports clubs, and industrial buildings. Building material was not examined because most buildings in which cases and controls were located were wood framed, and variation was too small to examine analytically.

Buildings damage was determined from building inspection data. After the earthquake, safety inspections of buildings were conducted in areas that were heavily damaged and also in response to requests from building owners. Each inspected building was assigned a level of damage related to the potential for decreased life safety. For these analyses, a building was classified as "damaged" if damage to structural elements were found or if the structural safety of the building was in doubt. $^{25}$ Buildings that were not inspected were included in the category of "no damage" for this analysis. This is a conservative assumption, but probably accurate because the absence of an inspection indicates that the building location did not indicate high risk for damage or that the owners/ occupants did not feel sufficient risk to request an inspection. Building information was obtained by linking case and control addresses to the Los Angeles County Tax Assessor's Roll and the City of Los Angeles "Northridge Earthquake 1994 Permit Database".

\section{Statistical analysis}

Conditional logistic regression for matched pairs was conducted using SAS 8.12. ${ }^{26}$ Likelihood 95\% confidence intervals (CI) were calculated to determine the precision of the estimates. Odds ratios were interpreted as risk ratios because all the necessary assumptions, including rarity of outcome, are met. The MMI scale was dichotomized as levels I through VII and levels VIII through IX because damage to seismically well designed buildings would not be expected below level VIII. ${ }^{2}$ Peak ground acceleration ranged from $7.6 \% \mathrm{~g}$ to $93.4 \% \mathrm{~g}$ and was modeled as a continuous variable using 10 point increments. Distance from the rupture plane ranged from 5.0 $\mathrm{km}$ to $69.9 \mathrm{~km}$ and was modeled as a continuous variable with $10 \mathrm{~km}$ increments.

Three models were used to assess each of the three risk factor categories. Seismic factors were modeled using the age and gender matched pairs and controlling for building characteristics. Personal factors were modeled using the location 
Table 2 Distribution of seismic/geophysical characteristics and risk of injury using age and gender matched controls

\begin{tabular}{|c|c|c|c|c|c|}
\hline \multirow[b]{2}{*}{ Characteristic } & \multirow[b]{2}{*}{ Cases $(n=103)$} & \multirow{2}{*}{$\begin{array}{l}\text { Location matched } \\
\text { controls }\end{array}$} & \multicolumn{3}{|c|}{ Age/gender matched controls* } \\
\hline & & & Controls & OR & $95 \% \mathrm{Cl}$ \\
\hline Mean distance from the earthquake rupture plane (range) in $\mathrm{km}$ & $16.3(5.0-48.6)$ & $16.5(5.2-50.5)$ & $34.6(5.2-69.9)$ & 0.9 & 0.8 to 0.9 \\
\hline \multicolumn{5}{|l|}{ Modified Mercalli intensity scale, number $(\%) \ddagger$} & 1.6 to 3.3 \\
\hline VII and below & $32(31.1)$ & $30(29.1)$ & $88(85.4)$ & 1 & \\
\hline VIII and above & 71 (68.9) & $73(70.9)$ & $15(14.6)$ & 16.5 & 5.8 to 65.1 \\
\hline \multicolumn{6}{|l|}{ Number (\%) by soil type } \\
\hline Rock & $19(18.4)$ & $16(15.5)$ & $25(24.3)$ & 1 & \\
\hline Sedimentary soil & $84(81.6)$ & $87(84.5)$ & $78(75.7)$ & 0.8 & 0.4 to 1.8 \\
\hline
\end{tabular}

* Models are controlled for building factors. Model fit was assessed using likelihood ratio tests. All models had $\chi^{2}>36.1$ and $p$ values $<0.0001$.

tPeak ground acceleration refers to the strongest ground motion at each location, and is measured as the percent gravity.

$\ddagger$ Modified Mercalli intensity scale divides intensity into 12 levels based on qualitative shaking experience. At level VII, no damage to seismically well

designed structures would be expected. Above this level, some damage to all types of buildings could be expected.

$\mathrm{Cl}$, confidence interval; OR, odds ratio.

matched pairs and controlling for building characteristics. Building factors, which did not serve as a matching variable, were modeled using both: (1) the location matched pairs, controlling for age and gender, and (2) the age and gender matched pairs, controlling for PGA and MMI. Thus, each group of factors could be examined as independent risks for injury while controlling for the other factors as confounders. Model fit was assessed through likelihood ratio tests. All models had a $\chi^{2}>30.9$ with very low p values, indicating a good fit.

\section{RESULTS}

\section{Seismic and geophysical characteristics}

Cases were located an average of $16.3 \mathrm{~km}$ from the earthquake rupture plane and experienced an average peak ground acceleration of $56.5 \% \mathrm{~g}$ (table 2 ). Sixty nine percent experienced a shaking intensity of MMI VIII or greater, which corresponds to heavily felt shaking, likely content displacement, and the potential for considerable damage in ordinary structures. Location matched controls had similar averages, ranges, and distributions to cases on all seismic variables, which indicates successful matching.

While controlling for age, gender, and building characteristics, all seismic factors except soil type were strongly predictive of injury (table 2). Every kilometer increase in distance from the rupture plane led to a $10 \%$ reduction in the risk of injury. Injury risk decreased $70 \%$ with every $10 \mathrm{~km}$ (6.2 miles) increase in distance from the rupture plane. Peak ground acceleration was a strong predictor of injury, with every $10 \% \mathrm{~g}$ increase in acceleration leading to 2.2 times the injury risk (95\% likelihood CI 1.6 to 3.3). At the highest level of PGA, individuals had approximately 20 times the risk of injury compared with those at the lowest level. Individuals experiencing MMI levels of VIII or IX had an increased injury risk of 16.5 , although this estimate had a broad confidence interval (95\% CI 5.8 to 65.1 ).
Since the seismic variables of distance, PGA, and MMI each attempt to measure the local strength of the earthquake, they overlap in the underlying construct being measured. Thus, we do not have a theoretical basis to mutually control for these variables or on which to expect interaction. Interactions were therefore not examined in mutually controlled models.

\section{Individual characteristics}

The mean age for cases was 55.0 years, and $38.8 \%$ were aged 65 and over (table 3). Age matched controls were similar with regard to mean age, proportion 65 and over, and gender distribution, which indicates successful matching. The average age for location matched controls was 46.8 years with a range of 21 to 98 . Thirty five percent of cases and age and gender matched controls were male, compared with $57.3 \%$ of location matched controls.

Every 10 year increase in age over age 18 led to a $30 \%$ increase in injury risk. Individuals over age 65 were 2.9 times more likely to be injured than younger individuals (95\% CI 1.2 to 7.4). Females were 2.4 times more likely to be injured than males (95\% CI 1.2 to 5.1 ). There was no significant interaction between age and gender, indicating, for example, that females over age 65 have the same increase in risk over 65 year old males as younger females would have over like aged males.

\section{Building characteristics}

Building factors were examined using both age and gender and location matched case-control pairs (table 4). Although estimates using each control group revealed the same trends, the models using the location matched pairs and controlling for age and gender had higher $\chi^{2}$ values for the likelihood ratio tests, indicating a better model fit.

Compared with single unit residential structures, individuals in multiple unit residential structures had 3.8 times the risk of injury for location matched and 2.9 times the risk for

Table 3 Distribution of individual characteristics and risk of injury using location matched controls

\begin{tabular}{|c|c|c|c|c|c|}
\hline \multirow[b]{2}{*}{ Characteristic } & \multirow[b]{2}{*}{ Cases } & \multirow{2}{*}{$\begin{array}{l}\text { Age matched } \\
\text { controls }\end{array}$} & \multicolumn{3}{|c|}{ Location matched controls* } \\
\hline & & & Controls & OR & $95 \% \mathrm{Cl}$ \\
\hline Mean age (range) $† \ddagger$ & $55.0(18-95)$ & $54.8(18-97)$ & 46.8 (21-98) & 1.3 & 1.1 to 1.6 \\
\hline $\begin{array}{l}\text { Number }(\%) \text { above age } 65 \neq \\
\text { Number }(\%) \text { by gender } \neq\end{array}$ & $40(38.8)$ & $39(37.9)$ & $18(17.5)$ & 2.9 & 1.2 to 7.4 \\
\hline Male & $36(35.0)$ & $36(35.0)$ & $59(57.3)$ & 1 & \\
\hline Female & $67(65.0)$ & $67(65.0)$ & $44(42.7)$ & 2.4 & 1.2 to 5.1 \\
\hline
\end{tabular}

* Models are controlled for building factors. Model fit was assessed using likelihood ratio tests. All models had $\chi^{2}>36.1$ and $p$ values $<0.0001$

tOdds ratio (OR) for age per 10 years.

$\ddagger$ Adjusted for age and gender.

$\mathrm{Cl}$, confidence interval. 
Table 4 Distribution of building characteristics and risk of injury using location and age and gender matched controls

\begin{tabular}{|c|c|c|c|c|c|c|c|}
\hline \multirow[b]{2}{*}{ Characteristic } & \multirow[b]{2}{*}{ Cases } & \multicolumn{3}{|c|}{ Location matched controls* } & \multicolumn{3}{|c|}{$\begin{array}{l}\text { Age/gender matched } \\
\text { controlst }\end{array}$} \\
\hline & & Controls & OR & $95 \% \mathrm{Cl}$ & Controls & OR & $95 \% \mathrm{Cl}$ \\
\hline \multicolumn{8}{|l|}{ Building type } \\
\hline Residential single unit & $45(43.7)$ & 70 (68.0) & 1 & & 75 (72.8) & 1 & - \\
\hline Residential multiple unit & $47(45.6)$ & $29(28.2)$ & 3.8 & 1.7 to 9.7 & $24(23.3)$ & 2.9 & 1.2 to 8.3 \\
\hline Commercial/other & 11 (10.7) & $4(3.9)$ & 6.4 & 1.4 to 47.6 & $4(3.9)$ & 6.9 & 1.3 to 49.5 \\
\hline \multicolumn{8}{|l|}{ Building date } \\
\hline Built before 1950 & $22(21.4)$ & $19(18.4)$ & 1 & & $38(36.9)$ & 1 & - \\
\hline Built 1950-69 & 40 (38.9) & $66(64.1)$ & 0.4 & 0.1 to 0.9 & $46(44.7)$ & 0.8 & 0.3 to 2.1 \\
\hline Built 1970 or later & 41 (39.8) & $18(17.5)$ & 1.9 & 0.7 to 5.2 & 19 (18.4) & 2.8 & 0.9 to 10.6 \\
\hline \multicolumn{8}{|l|}{ Damaged } \\
\hline No & 79 (76.7) & 97 (94.2) & 1 & & 101 (98.1) & & \\
\hline Yes & $24(23.3)$ & $6(5.8)$ & 8.5 & 2.4 to 56.7 & $2(1.9)$ & $N / A$ & $N / A$ \\
\hline \multicolumn{8}{|c|}{$\begin{array}{l}{ }^{*} \text { Controlled for age and gender. Model fit was assessed using likelihood ratio tests. All models had } \chi^{2}>70.9 \\
\text { and } p \text { values }<0.0001 \text {. } \\
\text { tControlled for modified Mercalli intensity scale and peak ground acceleration. Model fit was assessed using } \\
\text { likelihood ratio tests. All models had } \chi^{2}>30.9 \text { and } p \text { values }<0.0001 \text {. } \\
\text { Cl, confidence interval; N/A, not applicable; OR, odds ratio. }\end{array}$} \\
\hline
\end{tabular}

age and gender matched controls. Individuals in buildings categorized as commercial/other use had over six times the injury risk for both types of matched pairs. Individuals in structures built between 1950 and 1969 had slightly lower injury risks than those in buildings built before 1950, but this finding was only significant when using location matched pairs. Individuals in buildings built in 1970 or later had nonsignificantly raised injury risks using both types of matched pairs.

Being in a damaged building led to an increased injury risk of 8.5 using location matched pairs (95\% CI 2.4 to 56.7). However, there were only six controls in damaged structures, and with such a small cell size this estimate is highly unstable. There were too few controls in damaged buildings to provide an estimate using age and gender matched pairs. Only $23.3 \%$ of cases were in damaged buildings, indicating that there are many causal pathways for injury other than structural damage, such as falls or crushing injuries from displaced furniture. No interactions between building variables were present. The lack of interaction could be due largely to the small sample size, which limits the ability to examine multiple exposures precisely.

\section{DISCUSSION}

We found that seismic, structural, and individual characteristics are each individual contributors to the risk of physical injury from an earthquake. Females and the elderly have consistently been identified as having increased risk for death and injury in an earthquake, but few studies controlled for seismic or building confounders. ${ }^{91-14}$ It was previously unknown, therefore, if age and gender risk were due to intrinsic factors related to being elderly or female or instead to the distribution of these individuals in different seismic areas and buildings. This study's findings indicate that the elderly and females do have an independent risk. This could be due to decreased resiliency to injury or perhaps in the elderly to a decreased ability to take protective action. For females, increased injury risk may be introduced when mothers attempt to reach and protect children. While these findings are consistent with other literature, the causes for this pattern are not well explained.

Building damage was a strong predictor of injury, but other building factors were also important risk factors. Buildings constructed after 1970 were expected to protect against earthquake related injury because most of the current seismic building codes in California were introduced and implemented after $1970 .^{27}$ However, we found that buildings built after 1970 led to an increased risk for injury. One explanation for this pattern may be related to the relationship between building motion and injury. Depending upon construction material newer buildings are constructed to be more flexible during earthquakes so that they sway more without collapsing. This increased motion may lead to an increased risk for injuries related to building movement but not building damage, such as from falling or being struck by shifting contents.

A number of important risk factors that have been identified in previous literature could not be measured with the available data. Buildings with many floors and an individual's location on higher floors lead to increased risk of injury. ${ }^{14-16}$ We could not determine on which floor individuals in this study were located. Adobe, concrete, and masonry buildings have been identified as more dangerous than wood framed structures. ${ }^{214}{ }^{17-19} 27$ Building material was not included in this analysis because most of the residential buildings in Southern California are wood framed and variation in building material was too small to examine analytically. Attempting to escape from buildings has been documented as both a protective factor for death ${ }^{14-16}$ and a risk factor for death and injury. ${ }^{13}$ These are not necessarily contradictory, however, because exiting from a poorly built collapsing structure may protect against death, while attempts to exit buildings that do not collapse may increase risk for injury.

Several limitations should be considered when interpreting the results of this study. Controls were drawn from a telephone survey, and many displaced individuals may not be accessible by phone after an earthquake. Phone surveys are vulnerable to bias because of low response rates, and response to this survey was approximately $50 \%$. Because the control pool was limited, controls were used multiple times. This could lead to artificially high homogeneity among the controls that could introduce bias. Despite these limitations, this study was a unique opportunity to examine multiple data sources.

Significant advances in earthquake safety can be made if similar analyses can be conducted for multiple earthquakes. With accumulated risk information, it will be possible not only to determine the independent role of these variables on injury but also to identify how different earthquakes, populations, and building types interact to increase or decrease the potential for injury in major earthquakes. For example, prevention efforts focusing on the elderly could include programs to assist older individuals to find a seismically stable residence and securing their heavy furniture, prioritization of search and rescue efforts to areas within a community where elderly 


\section{Key points}

- Deaths and injuries from earthquakes vary dramatically based on characteristics of the earthquake, the environment, and the population where the earthquake strikes.

- Previous research has shown that factors such as age and gender, building characteristics, and shaking intensity are related to the likelihood of being killed in an earthquake.

- To examine risk of earthquake injury in the 1994 Northridge, California earthquake, we matched, by age and gender and by location, individuals with earthquake injuries to individuals exposed to the earthquake but not injured.

- Seismic characteristics including peak ground acceleration, shaking intensity, and distance to the earthquake rupture plane, individual characteristics including age and gender, and building characteristics including building occupancy type and damage were independently related to earthquake injury.

- The causal pathway for injuries in earthquakes is multifactoral, and this provides the potential for several types of prevention approaches to be successful in preventing and reducing injury.

populations are concentrated, and campaigns to focus prevention messages on the highest risk residences. Better knowledge of the multiple risk factors for injury and their relationship with each other can help service providers identify vulnerable populations, help search and rescue units better focus their searches based on the profile of the earthquake and the population, and aid preparedness efforts through better identification of risk profiles leading to injury.

\section{ACKNOWLEDGEMENTS}

This research was supported by the Southern California Injury Prevention Research Center (CDC CCR 903622), the California Department of Health Services Emergency Preparedness and Injury Control Branch (95-23008 A2), the UCLA Center for Public Health and Disaster Relief (NSF CMS-9416470, CMS-9411982, and CMS9900062; LAC-DHS R41867 and 953124), and the University of Iowa Injury Prevention Research Center (CDC CCR 703640).

\section{Authors' affiliations}

C Peek-Asa, lowa Injury Prevention Research Center, University of lowa College of Public Health, lowa City, lowa

M Ramirez, Southern California Injury Prevention Research Center, UCLA School of Public Health, Los Angeles, California

H Seligson, ABS Consulting (formerly EQE International), Center for Advanced Planning and Research, Irvine, California

K Shoaf, Center for Public Health and Disasters, UCLA School of Public Health, Los Angeles, California

\section{REFERENCES}

1 Alexander $\mathbf{D}$. The health effects of earthquakes in the mid-1990's. Disasters 1996:20:231-47.

2 Noii EK. Earthquakes. The public health consequences of disasters. New York: Oxford University Press, 1997: 135-78.

3 Wyss M, Wiemer S. Change in the probability for earthquakes in Southern California due to the Landers magnitude 7.3 earthquake. Science 2000;290: 1334-8.

4 Alexander D. Spatial aspects of earthquake epidemiology. Proceedings of the International Workshop on Earthquake Injury Epidemiology for Mitigation and Response. Baltimore, MD: Johns Hopkins University, 1989: 82-94.
5 Durkin $M$. Fatalities, nonfatal injuries, and medical aspects of the Northridge earthquake. In: Woods MC, Seiple WR, eds. The Northridge California, earthquake of 17 January 1994. Sacramento, CA: California Department of Conservation, Division of Mines and Geology Special Publication \#1 16, 1996: 247-54.

6 EQE International and ABS Group. Seattle (Nisqually), Washington earthquake of February 29, 2001. An EQE Briefing. Oakland, CA: EQE International, 2000: 1-8.

7 Tanaka H, Oda J, Iwai A, et al. Morbidity and mortality of hospitalized patients after the 1995 Hanshin-Awaji earthquake. Am J Emerg Med 1999;17:186-91.

8 de Ville de Goyet C, del Cid E, Romero A, et al. Earthquake in Guatemala: epidemiologic evaluation of the relief effort. Bull Pan Am Health Organ 1976;10:95-109.

9 Peek-Asa C, Kraus JF, Bourque LB, et al. Fatal and hospitalized injuries resulting from the 1994 Northridge earthquake. Int J Epidemiol 1998;27:459-65.

10 Peek-Asa C, Ramirez M, Shoaf K, et al. GIS mapping of earthquake-related deaths and hospital admissions from the 1994 Northridge, California, earthquake. Ann Epidemiol 2000;10:5-13.

11 Armenian HK, Melkonian A, Noji EK, et al. Deaths and injuries due to the earthquake in Armenia: a cohort approach. Int J Epidemiol 1997;26:806-13

12 Osaki Y, Minowa M. Factors associated with earthquake deaths in the great Hanshin-Awaji earthquake, 1995. Am J Epidemiol 2001;153:153-6.

13 Wagner R. A case-control study of risk factors for physical injury during the mainshock of the 1989 Loma Prieta earthquake in the county of Santa Cruz, California. Dissertation from Johns Hopkins University, Baltimore, MD; UMI Dissertation Services, Ann Arbor, Michigan, 1996.

14 Roces MC, White MD, Dayrit MM, et al. Risk factors for injuries due to the 1990 earthquake in Lizon, Philippines. Bull World Health Organ 1992;70:509-14.

15 Armenian HK, Noji EK, Oganesian AP. A case-control study of injuries arising from the earthquake in Armenia, 1988. Bull World Health Organ 1992; 70:251-7.

16 de Bruycker M, Greco D Lechat MF. The 1980 earthquake in Southern Italy-morbidity and mortality. Int J Epidemiol 1985;14:113-17.

17 Coburn AW, Pomonis A, Sakai S. Assessing strategies to reduce fatalities in earthquakes. Proceedings of the International Workshop on Earthquake Injury Epidemiology for Mitigation and Response. Baltimore, MD: Johns Hopkins University, 1989: 107-32.

18 Glass RI, Urrutia JJ, Sibony S, et al. Earthquake injuries related to housing in a Guatemalan village: aseismic construction techniques may diminish the toll of deaths and injuries. Science 1977;197:638-43.

19 Meli R. Modes of failure of buildings under seismic actions. Proceedings of the International Workshop on Earthquake Injury Epidemiology for Mitigation and Response. Baltimore, MD: Johns Hopkins University, 1989: 366-77.

20 Shoaf KI, Nguyen LH, Sareen HR, et al. Injuries as a result of California earthquakes in the past decade. Disasters 1998;22:218-35.

21 Dewey JW, Reagor BG, Dengler L, et al. Intensity distribution and isoseismal maps for the Northridge, California, earthquake of January 17, 1994. US Geological Service, US Geological Survey Open-File Report 95-92, 1995.

22 Wald DJ, Quitoriano V, Heaton TH, et al. TriNet "ShakeMaps": rapid generation of peak ground motion and intensity maps for earthquakes in Southern California. Earthquake Spectra 1999;15:537-56 (www.trinet.org).

23 Park S, Elrick S. Predictions of shear wave velocities in Southern California using surface geology. Bulletin of the Seismological Society of America 1998;88:677-85

24 Wald DJ, Heaton TH, Hudnut KW. The slip history of the 1994 Northridge, California, earthquake determined from strong ground motion, teleseismic, GPS, and leveling data. Bulletin of the Seismological Society of America 1996;86(suppl):49-70.

25 Applied Technology Council. Procedures for postearthquake safety evaluation of buildings. (ATC-20.) Redwood City, CA: Applied Technology Council, 1989: 1-89.

26 SAS Institute. SAS version 8.12. Cary, NC: SAS Institute, 2000.

27 EQE International and the California Office of Emergency Services. The Northridge earthquake of January 17, 1994: report of dato collection and analysis, part a: damage and inventory data. Oakland CA: EQE International and the GIS Group of the California Governor's Office of Emergency Services, May 1995. 